\title{
Decorin inhibits the proliferation of HepG2 cells by elevating the expression of transforming growth factor- $\beta$ receptor II
}

\author{
YANFENG LIU, XUESONG WANG, ZHAOHUI WANG, WENBO JU and DAWEI WANG \\ Department of Human Anatomy, College of Basic Medical Sciences, Beihua University, Jilin, Jilin 132013, P.R. China
}

Received March 23, 2015; Accepted April 19, 2016

DOI: $10.3892 /$ etm.2016.3572

\begin{abstract}
The aim of the present study was to investigate the effects of decorin (DCN) on the proliferation of human hepatoma HepG2 cells and the involvement of transforming growth factor- $\beta$ (TGF- $\beta$ ) signaling pathway. A vector containing DCN was transfected into HepG2 cells with the use of Lipofectamine 2000. Cell proliferation was assessed with an MTT assay, and western blot analysis was used to detect the protein expression of TGF- $\beta$ receptor I (TGF- $\beta$ RI), phosphorylated TGF- $\beta$ RI, p15 and TGF- $\beta$ RII. In addition, small interfering RNA (siRNA) silencing was performed to knock down the target gene. The results indicated that, compared with the control group, cell proliferation was significantly decreased in HepG2 cells transfected with DCN. In addition, DCN transfection significantly increased the phosphorylation level of TGF- $\beta$ RI in HepG2 cells. The expression of the downstream factor p15 was also significantly elevated in the DCN-transfected HepG2 cells. Furthermore, DCN transfection significantly elevated the expression level of TGF- $\beta$ RII in HepG 2 cells. By contrast, the silencing of TGF- $\beta$ RII significantly decreased the phosphorylation of TGF- $\beta$ RI in DCN-transfected HepG2 cells. In addition, TGF- $\beta$ RII silencing abolished the effects of DCN on the proliferation of HepG 2 cells. In conclusion, DCN elevated the expression level of TGF- $\beta$ RII, increased the phosphorylation level of TGF- $\beta$ RI, enhanced the expression of p15, and finally inhibited the proliferation of HepG2 cells. These findings may contribute to the understanding of the role of DCN in the pathogenesis of hepatic carcinoma and assist in the disease treatment.
\end{abstract}

\section{Introduction}

Decorin (DCN) is one of the important members of the small leucine-rich proteoglycan family, which is mainly composed of the $44-\mathrm{kD}$ core proteins and the dermatan sulfate side chains $(1,2)$. DCN is the main component of the extracellular

Correspondence to: Dr Dawei Wang, Department of Human Anatomy, College of Basic Medical Sciences, Beihua University, 3999 Binjiang East Road, Jilin, Jilin 132013, P.R. China

E-mail: wangdw5@163.com

Key words: HepG 2 cells, transforming growth factor- $\beta$ receptor II, decorin, cell proliferation matrix (ECM), serving an important role in maintaining the biological activity of the ECM protein in general, regulating the cell proliferation and differentiation, and preventing tissue fibrosis (3-6). Furthermore, DCN has been found to have significant antitumor effects (7). Since DCN is widely expressed in the microenvironment of normal and tumor tissues, it may influence the biological activity of the tumor cells by affecting the matrix structure and regulating various receptors associated with cell proliferation and survival, in order to further exert an antitumor effect $(7,8)$. Currently, the expression of DCN in various tumor types and its inhibitory effects on tumor cell proliferation have been intensively investigated (9). However, the role of DCN in hepatic carcinoma has not yet been fully established.

The signaling pathways involved in the action of DCN include the following: The regulation of the epidermal growth factor receptor (EGFR) and other ErbB family members, and the subsequent activation of the MAPK signaling pathway (10-12); the modulation of insulin-like growth factor receptor (IGFR) and low-density lipoprotein receptor-related protein 1 , and the further activation of the phosphoinositide-3 kinase/protein kinase $\mathrm{B} /$ mammalian target of rapamycin pathway (13-16); and the regulation of the transforming growth factor- $\beta$ (TGF- $\beta$ ) pathway, including TGF- $\beta 1$, TGF- $\beta 2$, and TGF- $\beta 3(17,18)$. In particular, the TGF- $\beta$ signaling pathway serves different roles at different stages in the development of hepatic carcinoma. At the early stage, TGF- $\beta$ acts as a tumor suppressor, inhibiting cell proliferation and enhancing cellular differentiation or apoptosis $(19,20)$. However, at the later stage, TGF- $\beta$ gradually loses its antiproliferative effects, and subsequently stimulates angiogenesis, inhibits immune responses and promotes ECM formation, which facilitates the cell proliferation and tumor metastasis $(19,20)$. In the activation of the TGF- $\beta$ signaling pathway, TGF- $\beta$ binds with the extracellular end of the TGF- $\beta$ receptor II (TGF- $\beta$ RII) to form a complex, which is able to phosphorylate TGF- $\beta$ RI, further regulating the cell proliferation and differentiation via the Smad signaling pathway (21-23). It has been reported that DCN may interact with TGF- $\beta$ and modulate the signaling pathway $(24,25)$. However, it has not yet been established whether there is direct interaction between DCN and TGF- $\beta$ Rs.

In the present study, the effects of DCN on the proliferation of human hepatoma HepG2 cells and the involvement of the TGF- $\beta$ signaling pathway were investigated. The results demonstrated that DCN may elevate the expression of TGF- $\beta$ RII, enhance the phosphorylation of TGF- $\beta$ RI and then induce the 
overexpression of p15 protein, thus inhibiting the proliferation of HepG 2 cells. Furthermore, knockdown of TGF- $\beta$ RII would result in the attenuation of the inhibiting effect of DCN on HepG2 cell proliferation.

\section{Materials and methods}

Cell line and culture. Human hepatoma HepG2 cells were obtained from Thermo Fisher Scientific, Inc. (Gaithersburg, MD, USA). These cells were cultured in Dulbecco's modified Eagle's medium supplemented with $10 \%$ fetal bovine serum (Invitrogen; Thermo Fisher Scientific, Inc., Carlsbad, CA, USA). The cells were divided into the four following groups: i) Control group, in which the cells were untreated; ii) DCN group, in which the cells were transfected with DCN; iii) siRNA group, in which the cells were transfected with mismatch-siRNA; and iv) DCN+siRNA, in which the cells were transfected with DCN+siRNA.

Cell transfection. The pcDNA5/FRT vector (Invitrogen; Thermo Fisher Scientific, Inc.), harboring an FRT site and a cDNA fragment containing DCN, was transfected into the HepG2 cells using Lipofectamine 2000 transfection reagent (cat. no. 11668072; Invitrogen; Thermo Fisher Scientific, Inc.), according to the manufacturer's instructions. Enhanced green fluorescent protein was used as the positive control. In order to detect the transfection efficiency, the cells were transfected with an enhanced green fluorescent protein-containing plasmid, and then stained with DAPI for 5 min. Fluorescence was detected with the IX83 microscope (Olympus Corp., Tokyo, Japan). The percentage of cells with green fluorescence was calculated to express the transfection efficiency.

Small interfering RNA (siRNA) silencing. siRNAs targeting DCN were purchased from Guangzhou RiboBio Co., Ltd. (Guangzhou, China) with the following sequences: i) 5'-GAG GGCAUGUAGACGGUUA dTdT-3', and 3'-dTdT CUCCCG UACAUCUGCCAAU-5'; ii) 5'-ACAAUAUGCUACCUCCAAA dTdT-3', and 3'-dTdT UGUUAUACGAUGGAGGUUU-5'; and iii) 5'-GACUGGAUCCAUACAAUAU dTdT-3', and 3'-dTdT CUGACCUAGGUAUGUUAUA-5'. siRNA (30 nM) was used to silence DCN, and the mismatch-siRNA, i.e. the non-sense RNS sequence, was used as the control. The transfection was performed with Lipofectamine 2000, according to the manufacturer's instructions. After $48 \mathrm{~h}$, the cells were collected and subjected to analysis.

Reverse transcription-quantitative polymerase chain reaction $(R T-q P C R)$. Total RNA was extracted with the SYBR Premix Ex Taq (Takara Bio Inc., Kyoto, Japan), and then reverse transcribed into cDNA with the M-MLV reverse transcription kit (Takara Bio Inc.), according to the manufacturer's instructions. The primer sequences used in qPCR were as follows: DCN forward, 5'-TCGCTCGAGATTTTTTTTTATCAAGAGGG-3', and reverse, 5'-TCGGCGGCCGCGACAAGAATGAGACTT TAATC-3'; TGF- $\beta$ RII forward, 5'-GTGTGGAGCAACATG TGGAACTCTA-3', and reverse, 5'-TTGGTTCAGCCACTG CCGTA-3'; $\beta$-actin forward, 5'-CATGTACGTTGCTATCCA GGC-3', and reverse, 5'-CTCCTTAATGTCACGCACGAT-3'. The $25 \mathrm{ml}$ PCR reaction system contained $12.5 \mu$ l SYBR Premix
Ex Taq (Takara Bio Inc.), $1 \mu \mathrm{l}$ of each primer, $2 \mu \mathrm{l}$ template and $8.5 \mu \mathrm{l}$ double-distilled $\mathrm{H}_{2} \mathrm{O}$. The reaction conditions were as follows: Denaturation at $95^{\circ} \mathrm{C}$ for $30 \mathrm{sec}$; then $95^{\circ} \mathrm{C}$ for $5 \mathrm{sec}$ and $60^{\circ} \mathrm{C}$ for $20 \mathrm{sec}$, for a total of 40 cycles. The relative expression of the target gene was calculated with the $2^{-\Delta \Delta C q}$ method (26). Experiments were performed in triplicate.

MTT assay. Cellular proliferation was assessed by the MTT assay. Briefly, HepG2 cells were seeded onto the 96 -well plates at the density of 5,000 cells/well. After $48 \mathrm{~h}$, the culture medium was discarded, and $200 \mu 1$ MCDB 131 (cat. no. L-1202-500; Thermo Fisher Scientific, Inc., Gaithersburg, MD, USA) and $20 \mu 1$ MTT (Cell Proliferation kit I; cat. no. 11465007001; Roche, Indianapolis, IN, USA) were added into each well. After 3.5-h incubation, the solution was discarded and $100 \mu$ d dimethyl sulfoxide (DMSO; cat. no. D2650; Sigma-Aldrich, St. Louis, MO, USA) was added. After $10 \mathrm{~min}$, the DMSO solution was transferred into a new 96-well plate, and the absorbance at $490 \mathrm{~nm}$ was read on a microplate reader (iMark; Bio-Rad Laboratories, Inc., Hercules, CA, USA).

Western blot analysis. The protein expression levels of TGF- $\beta$ RI, phosphorylated (p)TGF- $\beta$ RI, TGF- $\beta$ RII and p15 were detected by western blot analysis. Briefly, cells were cultured on 6 -well plates at the density of 20,000 cells/well. After transfection, cells from all the control and transfection groups were collected and lysed on ice with the lysis buffer (cat. no. 74255; Sigma-Aldrich). A total of $30 \mu \mathrm{g}$ protein sample was subjected to $10 \%$ SDS-PAGE, and electronically transferred onto a polyvinylidene difluoride membrane. The membrane was blocked with $50 \mathrm{~g} / \mathrm{l}$ skimmed milk at room temperature for $1 \mathrm{~h}$, and then incubated at $4^{\circ} \mathrm{C}$ overnight with the following polyclonal rabbit anti-human primary antibodies: Anti-TGF- $\beta$ RI antibody (dilution, 1:5,000; cat. no. ab31013), anti-pTGF- $\beta$ RI antibody (dilution, 1:5,000; cat. no. ab112095), anti-p15 antibody (dilution, 1:5,000; cat. no. ab53034), and anti-TGF- $\beta$ RII (dilution, 1:2,000; cat. no. ab61213; all from Abcam, Cambridge, MA, USA). Next, the membrane was incubated with goat anti-rabbit horseradish peroxidase-conjugated $\operatorname{IgG}$ secondary antibody (dilution, 1:1,000; cat. no. sc-2030; Santa Cruz Biotechnology, Inc.) at room temperature for $1 \mathrm{~h}$. The protein bands were visualized using an enhanced chemiluminescence detection kit (Sigma-Aldrich). Image Lab software (version 3; Bio-Rad Laboratories, Inc., Hercules, CA, USA) was used to acquire and analyze the images. GAPDH was used as the control.

Statistical analysis. Data are expressed as the mean \pm standard deviation. SPSS version 13.0 (SPSS, Inc., Chicago, IL, USA) software was used for the statistical analysis. The Student's t-test was used for pairwise comparison, while analysis of variance was performed for multiple comparison. $\mathrm{P}<0.05$ was considered to indicate statistically significant differences.

\section{Results}

DCN transfection inhibits the proliferation of HepG2 cells. The vector containing a DCN fragment was transfected into the HepG2 cells using Lipofectamine 2000, and the mRNA expression of DCN was detected with RT-qPCR. As shown in Fig. 1A, the transfection efficiency was $>90 \%$. The qPCR 
A
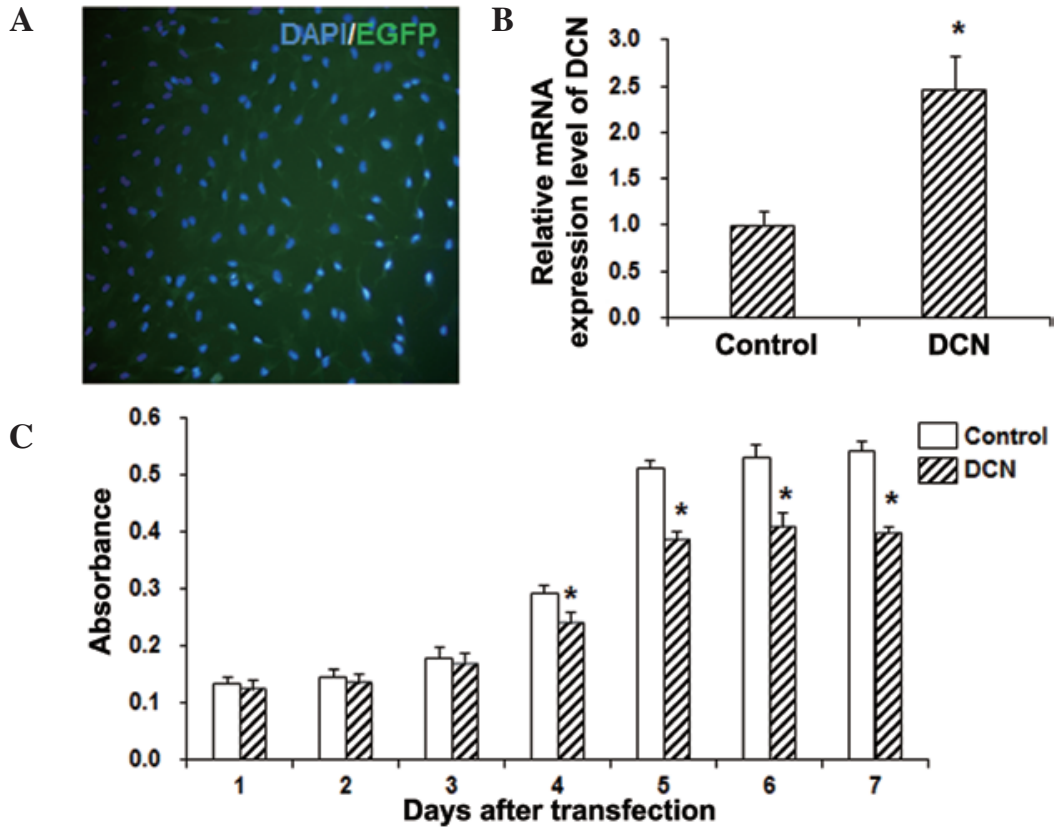

Figure 1. DCN transfection inhibited the proliferation of HepG2 cells. (A) DCN was transfected into HepG2 cells with Lipofectamine 2000 (magnification, x100). (B) Statistical analysis of the DCN mRNA expression levels in HepG2 cells, detected with quantitative polymerase chain reaction. (C) Cell proliferation of HepG2 cells was assessed by MTT assay. Data are expressed as the mean \pm standard deviation. $\mathrm{P}<0.05$, vs. control group. DCN, decorin-transfected group; EGFP, enhanced green fluorescent protein.

results demonstrated that DCN was stably overexpressed in these HepG2 cells following transfection, and its expression significantly higher when compared with that in the control group $(\mathrm{P}<0.05$; Fig. 1B). In order to investigate the effects of DCN on the proliferation of HepG2 cells, an MTT assay was performed. The results revealed that, compared with the control group, the cell viability was significantly decreased in HepG2 cells transfected with DCN $(\mathrm{P}<0.05$; Fig. 1C). These results suggest that $\mathrm{DCN}$ is able to significantly inhibit the proliferation of HepG2 cells.

DCN induces TGF- $\beta R I$ phosphorylation and elevates p15 expression. To investigate the underlying mechanisms through which DCN inhibited the proliferation of HepG2 cells, the expression of cell proliferation-associated signaling pathways was detected by the western blot analysis. The results showed that, compared with the control group, no statistically significant differences were observed in the total TGF- $\beta$ RI protein expression level in the HepG2 cells transfected with DCN ( $>>0.05$; Fig. 2A). By contrast, the phosphorylation of TGF- $\beta$ RI was significantly increased in HepG2 cells following DCN transfection $(\mathrm{P}<0.05$; Fig. 2B). In addition, compared with the control group, the expression of the downstream factor p15 was significantly elevated in the DCN-transfected HepG2 cells $(\mathrm{P}<0.05$; Fig. 2C). These results suggest that DCN transfection is able to activate TGF- $\beta R I$ and elevate the expression of p15 in HepG2 cells, implying the involvement of the TGF- $\beta$ signaling pathway in the inhibitory effects of DCN on $\mathrm{HepG} 2$ cell proliferation.

$D C N$ increases the expression of TGF- $\beta$ RII in HepG 2 cells. In the TGF- $\beta$ signaling pathway, TGF- $\beta$ binds with the extracellular end of TGF- $\beta$ RII, and the complex formed can induce the phosphorylation of TGF- $\beta$ RI and regulate the downstream cell proliferation-associated signaling pathways via
Smad (20-22). Therefore, the expression levels of TGF- $\beta$ RII in DCN-transfected and control HepG2 cells were detected by the western blot analysis. The results demonstrated that, compared with the control group, DCN transfection significantly elevated the protein expression of TGF- $\beta$ RII in HepG2 cells $(\mathrm{P}<0.05$; Fig. 2D). These results suggest that TGF- $\beta$ RII may be involved in the inducing effect of DCN on TGF- $\beta$ RI phosphorylation.

TGF- $\beta R I I$ silencing abolishes the effects of DCN on TGF- $\beta$ signaling and Hep $\mathrm{G} 2$ cell proliferation. In order to further investigate the role of TGF- $\beta$ RII in DCN-induced phosphorylation of TGF- $\beta$ RI in HepG2 cells, TGF- $\beta$ RII was knocked down with siRNA silencing. RT-qPCR demonstrated that the mRNA expression level of TGF- $\beta$ RII was not significantly altered by the mismatch-siRNA treatment, while the TGF- $\beta$ RII mRNA expression level was significantly decreased in the siRNA silencing group $(\mathrm{P}<0.05 ; \mathrm{Fig}$. $3 \mathrm{~A})$. In addition, the results from western blot analysis showed that the siRNA silencing of TGF- $\beta$ RII alone did not induce significant alteration in TGF- $\beta$ RI phosphorylation in the HepG2 cells ( $\mathrm{P}>0.05$; Fig. 3B). However, TGF- $\beta$ RII silencing significantly decreased the phosphorylation of TGF- $\beta$ RI in DCN+siRNA-transfected HepG2 cells, when compared with the DCN group ( $\mathrm{P}<0.05$; Fig. 3B). Furthermore, the MTT assay revealed that TGF- $\beta$ RII silencing abolished the inhibitory effects of DCN on the proliferation of HepG2 cells $(\mathrm{P}<0.05$; Fig. $3 \mathrm{C})$. These results suggest that TGF- $\beta$ RII is a key player in the DCN-induced pTGF- $\beta$ RI enhancement and HepG2 cell proliferation inhibition.

\section{Discussion}

In the present study, the results demonstrated that DCN transfection significantly inhibited the proliferation of HepG2 cells, in which the TGF- $\beta$ signaling pathway was found to 

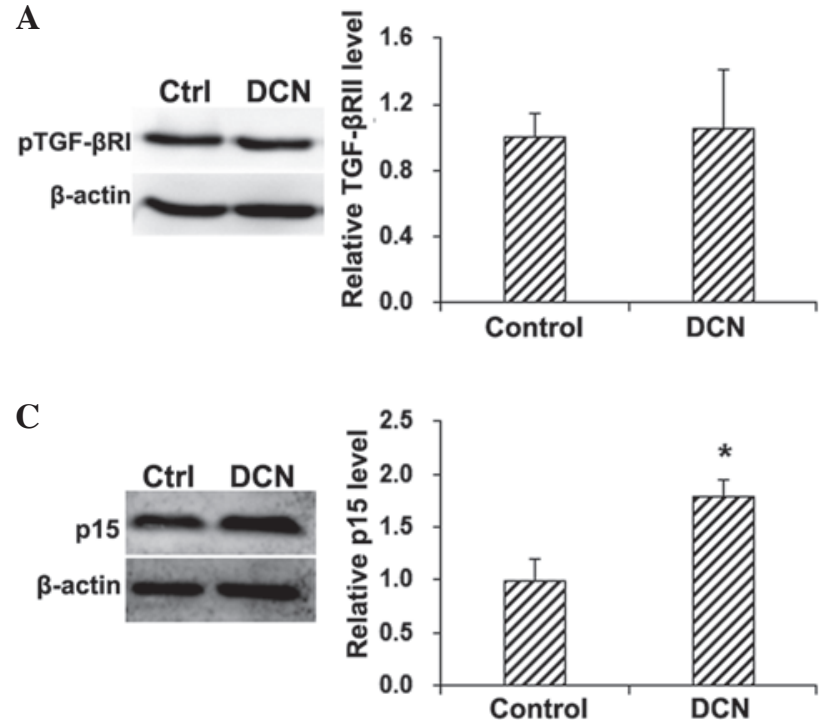
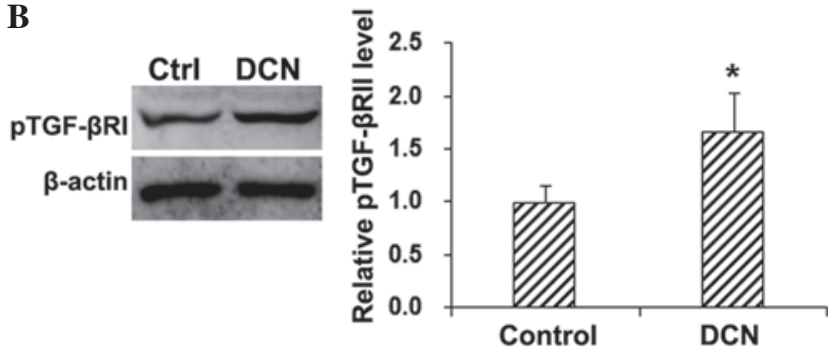

D
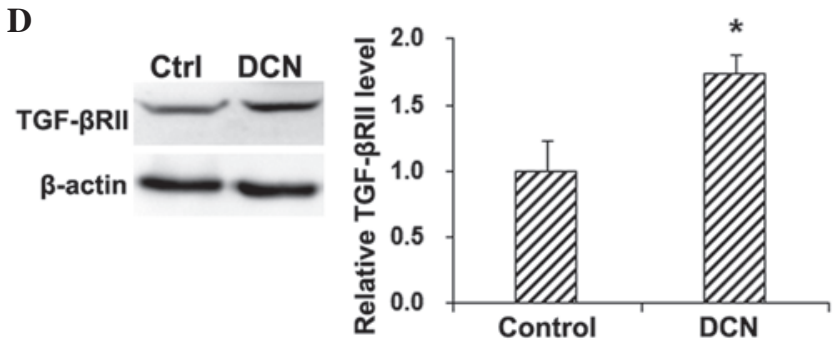

Figure 2. DCN affected the expression of proteins associated with the TGF- $\beta$ signaling pathway. The protein expression levels of (A) TGF- $\beta$ RI, (B) pTGF- $\beta$ RI, (C) p15 and (D) TGF- $\beta$ RII in DCN-transfected HepG2 cells were detected using western blot analysis. Data are expressed as the mean \pm standard deviation. "P<0.05, vs. control group. DCN, decorin-transfected group; TGF- $\beta$ R, transforming growth factor- $\beta$ receptor; pTGF- $\beta$ RI, phosphorylated TGF- $\beta$ RI; Ctrl, control.

A

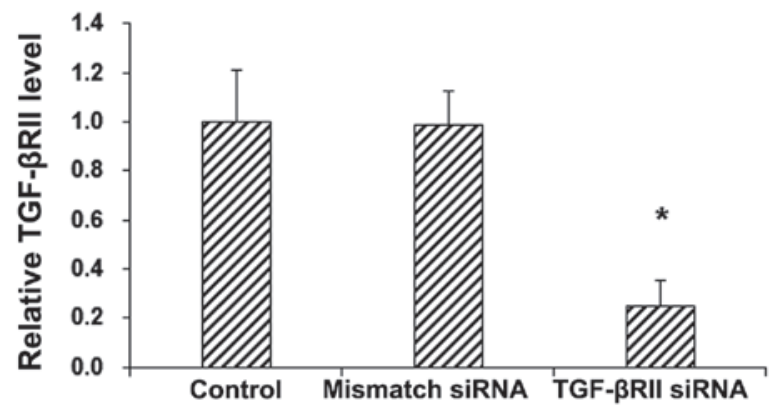

B
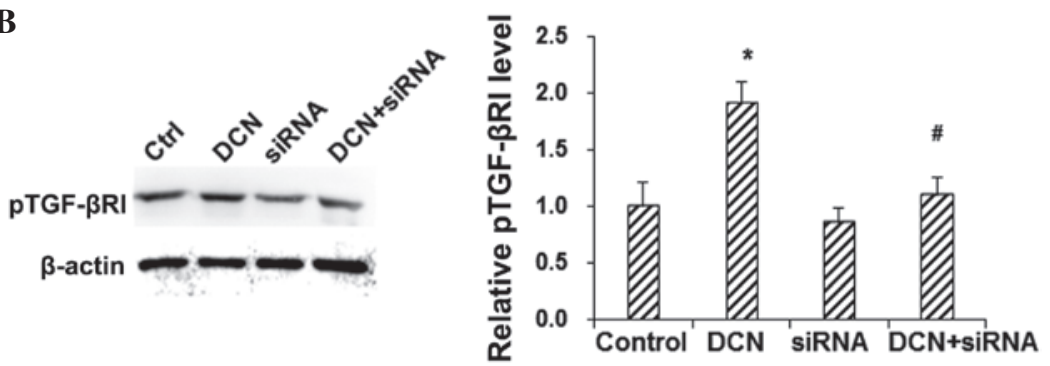

C

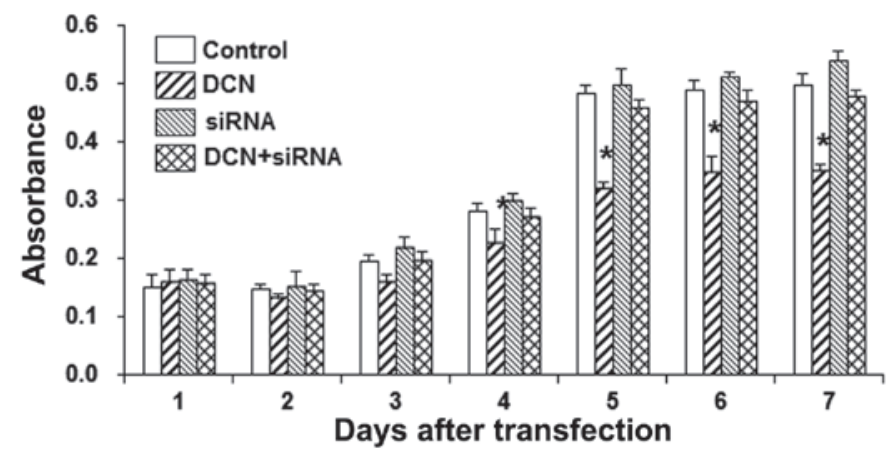

Figure 3. TGF- $\beta$ RII silencing abolished the effects of DCN on the TGF- $\beta$ signaling pathway and HepG 2 cell proliferation. (A) TGF- $\beta$ RII was silenced with siRNA in HepG2 cells. (B) Protein expression of pTGF- $\beta$ RI was detected by western blot analysis in HepG2 cells subjected to DCN transfection and/or TGF- $\beta$ RII silencing. (C) Cell proliferation of HepG2 cells subjected to DCN transfection and/or TGF- $\beta$ RII silencing was assessed by MTT assay. Data are expressed as the mean \pm standard deviation. ${ }^{~} \mathrm{P}<0.05$ vs. control group; ${ }^{~} \mathrm{P}<0.05$, vs. DCN group. Ctrl or Control, untreated group; DCN, decorin-transfected group; siRNA, mismatch-siRNA-transfected group; DCN+siRNA, DCN+siRNA-transfected group; TGF- $\beta$ R, transforming growth factor- $\beta$ receptor; pTGF- $\beta R$ I, phosphorylated TGF- $\beta R I$; siRNA, small interfering RNA; Ctrl, control. 
serve an important role. The DCN transfection elevated the phosphorylation level of TGF- $\beta$ RI in HepG2 cells, without affecting the total TGF- $\beta$ RI expression. The p15 protein is one of the key downstream factors of TGF- $\beta$ RI, whose activation may influence cell cycle-associated proteins, further inhibiting the cell proliferation (20-22). The current results showed that DCN transfection was able to significantly elevate the expression level of $\mathrm{p} 15$. Within cells, TGF- $\beta$ binds with TGF- $\beta$ RII to further phosphorylate TGF- $\beta$ RI (18). The present study results showed that DCN transfection increased the expression level of TGF- $\beta$ RII. In addition, when TGF- $\beta$ RII was silenced with siRNA, the phosphorylated TGF- $\beta$ RI in DCN-transfected HepG2 cells was significantly decreased, and the cell proliferation was also significantly inhibited.

Previous studies have shown that DCN inhibited the TGF- $\beta$ signaling pathway via binding with TGF- $\beta(16,23)$. The current results indicated that DCN transfection elevated the expression level of TGF- $\beta$ RII, which then activated the TGF- $\beta$ signaling pathway and inhibited the proliferation of HepG2 cells. Although HepG2 cells may not be an ideal model of the pathogenesis and development of hepatic carcinoma, the present study revealed the significance of the TGF- $\beta$ signaling pathway in the disease pathology. The TGF- $\beta$ signaling pathway is able to inhibit the cell proliferation and differentiation at the early disease stage. However, at the later stage, TGF- $\beta$ gradually loses its inhibitory effects, and thus promotes tumor metastasis (18). The present study results revealed that DCN enhanced TGF- $\beta$ RII expression, promoting the TGF- $\beta$ signaling pathway, which may represent the early event in the disease pathogenesis. However, further studies are still required to investigate the detailed mechanisms through which DCN functions on the TGF- $\beta$ signaling pathway.

In conclusion, the results of the present study showed that DCN transfection significantly elevated the expression of TGF- $\beta$ RII, increased the phosphorylation of TGF- $\beta$ RI, enhanced the expression of $\mathrm{p} 15$, and finally inhibited the proliferation of HepG 2 cells. Upon silencing TGF- $\beta$ RII with siRNA, the effects of DCN on the TGF- $\beta$ signaling pathway and the HepG2 cell proliferation were abolished. The current findings may contribute to the understanding of the role of DCN in the pathogenesis of hepatic carcinoma and the disease treatment.

\section{Acknowledgements}

This study was supported by a grant from the 'Twelfth Five-Year' Science and Technology Research Project of the Education Department of Jilin Province [no. (2012) 127].

\section{References}

1. Goldoni S, Owens RT, McQuillan DJ, Shriver Z, Sasisekharan R, Birk DE, Campbell S and Iozzo RV: Biologically active decorin is a monomer in solution. J Biol Chem 279: 6606-6612, 2004.

2. Scott PG, Dodd CM, Bergmann EM, Sheehan JK and Bishop PN: Crystal structure of the biglycan dimer and evidence that dimerization is essential for folding and stability of class I small leucine-rich repeat proteoglycans. J BiolChem 281: 13324-13332, 2006.

3. Kresse H and Schönherr E: Proteoglycans of the extracellular matrix and growth control. J Cell Physiol 189: 266-274, 2001.

4. Geng Y, McQuillan D and Roughley PJ: SLRP interaction can protect collagen fibrils from cleavage by collagenases. Matrix Biol 25: 484-491, 2006.
5. Rühland C, Schönherr E, Robenek H, Hansen U, Iozzo RV, Bruckner P and Seidler DG: The glycosaminoglycan chain of decorin plays an important role in collagen fibril formation at the early stages of fibrillogenesis. FEBS J 274: 4246-4255, 2007.

6. Reed CC and Iozzo RV: The role of decorin in collagen fibrillogenesis and skin homeostasis. Glycoconj J 19: 249-255, 2002.

7. Iozzo RV: Tumor stroma as a regulator of neoplastic behavior. Agonistic and antagonistic elements embedded in the same connective tissue. Lab Invest 73: 157-160, 1995.

8. BuraschiS,NeillT,OwensRT,IniguezLA,Purkins G,VadigepalliR, Evans B, Schaefer L, Peiper SC, Wang ZX and Iozzo RV: Decorin protein core affects the global gene expression profile of the tumor microenvironment in a triple-negative orthotopic breast carcinoma xenograft model. PLoS One 7: e45559, 2012.

9. Nyman MC, Sainio AO, Pennanen MM, Lund RJ, Vuorikoski S, Sundström JT and Järveläinen HT: Decorin in human colon cancer: Localization in vivo and effect on cancer cell behavior in vitro. J Histochem Cytochem 63: 710-720, 2015.

10. Santra M, Reed CC and Iozzo RV: Decorin binds to a narrow region of the epidermal growth factor (EGF) receptor, partially overlapping with but distinct from the EGF-binding epitope. J Biol Chem 277: 35671-35681, 2002.

11. Santra M, Eichstetter I and Iozzo RV: An anti-oncogenic role for decorin: Down-regulation of ErbB2 leads to growth suppression and cytodifferentiation of mammary carcinoma cells. J Biol Chem 275: 35153-35161, 2000.

12. Csordás G, Santra M, Reed CC, Eichstetter I, McQuillan DJ, Gross D, Nugent MA, Hajnóczky G and Iozzo RV: Sustained down-regulation of the epidermal growth factor receptor by decorin. A mechanism for controlling tumor growth in vivo. J Biol Chem 275: 32879-32887, 2000.

13. Schönherr E, Sunderkötter C, Iozzo RV and Schaefer L: Decorin, a novel player in the insulin-like growth factor system. J Biol Chem 280: 15767-15772, 2005.

14. Schaefer L, Tsalastra W, Babelova A, Baliova M, Minnerup J, Sorokin L, Gröne HJ, Reinhardt DP, Pfeilschifter J, Iozzo RV and Schaefer RM: Decorin-mediated regulation of fibrillin-1 in the kidney involves the insulin-like growth factor-1 receptor and mammalian target of rapamycin. Am J Pathol 170: 301-315, 2007.

15. Schönherr E, Sunderkötter C, Schaefer L, Thanos S, Grässel S, Oldberg A, Iozzo RV, Young MF and Kresse H: Decorin deficiency leads to impaired angiogenesis in injured mouse cornea. J Vasc Res 41: 499-508, 2004.

16. Schönherr E, Levkau B, Schaefer L, Kresse H and Walsh K: Decorin affects endothelial cells by akt-dependent and -independent pathways. Ann NY Acad Sci 973: 149-152, 2002.

17. Imai K, Hiramatsu A, Fukushima D, Pierschbacher MD and Okada Y: Degradation of decorin by matrix metalloproteinases: Identification of the cleavage sites, kinetic analyses and transforming growth factor-beta 1 release. Biochem J 322: 809-814, 1997.

18. Brown S, Melrose J, Caterson B, Roughley P, Eisenstein SM and Roberts S: A comparative evaluation of the small leucine-rich proteoglycans of pathological human intervertebral discs. Eur Spine J 21 (Suppl 2): S154-S159, 2012.

19. Barcellos-Hoff MH: Latency and activation in the control of TGF-beta. J Mammary Gland Biol Neoplasia 1: 353-363, 1996.

20. Halper J: Proteoglycans and diseases of soft tissues. Adv Exp Med Biol 802: 49-58, 2014.

21. Park C, Kim WS, Choi Y, Kim H and Park K: Effects of transforming growth factor beta (TGF-beta) receptor on lung carcinogenesis. Lung Cancer 38: 143-147, 2002.

22. Saji H, Nakamura H, Awut I, Kawasaki N, Hagiwara M, Ogata A Hosaka M, Saijo T, Kato Y and Kato H: Significance of expression of TGF-beta in pulmonary metastasis in non-small cell lung cancer tissues. Ann Thorac Cardiovasc Surg 9: 295-300, 2003.

23. Paik SY, Park YN, Kim H and Park C: Expression of transforming growth factor-beta 1 and transforming growth factor-beta receptors in hepatocellular carcinoma and dysplastic nodules. Mod Pathol 16: 86-96, 2003.

24. Schönherr E, Broszat M, Brandan E, Bruckner P and Kresse H: Decorin core protein fragment Leu155-Val260 interacts with TGF-beta but does not compete for decorin binding to type I collagen. Arch Biochem Biophys 355: 241-248, 1998.

25. Harper J: Proteoglycans and diseases of soft tissues. In: Progress in Heritable Soft Connective Tissue Diseases. Springer, Dordrecht, pp49-58, 2014.

26. Livak KJ and Schmittgen TD: Analysis of relative gene expression data using real-time quantitative PCR and the $2^{-\Delta \Delta \mathrm{Ct}}$ method. Methods 254: 402-408,2001. 